\title{
Urinary interleukin-6 and tumour necrosis factor-alpha as early markers for diabetic nephropathy in children and adolescents with type 1 diabetes
}

\author{
Mona A Hana ${ }^{1}$, Sahar A Sharaf ${ }^{2}$, Mohamed M Ismail ${ }^{1}$, Marwa F Mira ${ }^{1}$, Marwa Taha $^{1}$, Mai M Mostafa ${ }^{1}$, \\ Hend M Soliman ${ }^{1}$
}

Sri Lanka Journal of Child Health, 2020; 49(3): 269-275

\begin{abstract}
Background: Diabetic nephropathy (DN) is the main cause of morbidity and mortality in young adults with type 1 diabetes mellitus (T1DM). The accuracy of albuminuria has been frequently questioned as a predictor and prognosticator of renal injury. Therefore, new urinary markers were investigated for the early detection of $\mathrm{DN}$.
\end{abstract}

Objectives: To assess the potential value of urinary interleukin-6 (IL-6) and tumour necrosis factoralpha (TNF- $\alpha$ ) as early markers for detection of DN in children and adolescents with T1DM.

Method: This case-control study was conducted on 50 children and adolescents with T1DM, aged $\leq 18$ years. Patients were classified according to their albumin/creatinine ratio (ACR) into two groups, normo-albuminuric and albuminuric, together with 25 age and sex-matched healthy controls. ACR, urinary IL-6 and TNF- $\alpha$ levels were assayed for patients and controls.

Results: Urinary interleukin-6/creatinine (IL-6/Cr) ratio of albuminuric patients was significantly higher compared to normo-albuminuric patients or controls. Urinary IL-6/Cr ratio $\geq 0.24 \mathrm{pg} / \mathrm{mg}$ was a significant cutoff value to detect albuminuria with $72 \%$ sensitivity and $52 \%$ specificity $(p=0.04)$. We did not observe different urinary TNF- $\alpha /$ creatinine (TNF- $\alpha / \mathrm{Cr}$ ) ratio in the studied groups, or between albuminuric and normo-albuminuric patients or controls.

${ }^{1}$ Diabetes, Endocrinology \& Metabolism Pediatric Unit (DEMPU), Department of Pediatrics, Faculty of Medicine, Cairo University, Cairo, Egypt

${ }^{2}$ Department of Clinical Pathology, Faculty of Medicine, Cairo University, Cairo, Egypt

*Correspondence: marwataha_8484@yahoo.com

orcid.org/ 0000-0001-5939-9923

(Received on 22 October 2019: Accepted after revision on 20 December 2019)

The authors declare that there are no conflicts of interest

Personal funding was used for the project.

Open Access Article published under the Creative

Commons Attribution CC-BY (c) (i)
Conclusions: Urinary IL-6/Cr ratio seems to be a promising new marker for early detection of $\mathrm{DN}$ in patients with T1DM, while urinary TNF- $\alpha / \mathrm{Cr}$ ratio showed no significant difference between diabetic patients and controls.

http://dx.doi.org/10.4038/sljch.v49i3.9146

(Key words: Type 1 diabetes mellitus, diabetic nephropathy, urinary interleukin-6, urinary tumour necrosis factor-alpha, albuminuria)

\section{Introduction}

Complications of diabetes mellitus (DM) include diabetic nephropathy (DN), retinopathy, and cardiovascular disease ${ }^{1}$. DN is the most serious microvascular complication and is the leading cause of chronic kidney disease, which frequently leads to end stage renal disease ${ }^{2}$. Microalbuminuria has been identified in clinical practice as the earliest predictor of DN but a high percentage of renal impairment occurs before the onset of microalbuminuria or even in the non-albuminuric state. Thus, urinary albumin levels may merely reflect an initial reversible stage of renal damage ${ }^{3}$. Therefore, detection of new predictive markers to use with microalbuminuria during the early stages of diabetic kidney disease would provide a chance of preventing or delaying the onset of irreversible consequences through prohibitive therapeutic interventions ${ }^{4}$. Hyperglycaemia can promote the expression of some pro-inflammatory cytokines, like interleukin-6 (IL-6) and tumour necrosis factor-alpha (TNF- $\alpha)$, which lead to a chronic subclinical inflammatory state in $\mathrm{DM}^{5}$. IL-6 is a pleiotropic cytokine and its serum level was found to have a significant correlation with the severity of diabetic glomerulopathy, kidney hypertrophy, and albumin excretion suggesting its role in the pathogenesis of $\mathrm{DN}^{6}$. TNF- $\alpha$ is a major contributor to inflammation, apoptosis and extracellular matrix accumulation in glomerular and tubular regions leading to alteration of glomerular filtration, tubular permeability and reabsorption ${ }^{3}$.

\section{Objectives}

To study urinary IL- 6 and TNF- $\alpha$ as early markers for detecting $\mathrm{DN}$ in children and adolescents having type 1 diabetes mellitus (T1DM). 


\section{Method}

A case-control study was conducted at the Diabetes, Endocrine \& Metabolism Paediatric Unit (DEMPU), Cairo University Children's Hospital in 50 children and adolescents with T1DM $>5$ years. They were classified based on their albumin/ creatinine ratio (ACR) into 2 groups. Group I $(\mathrm{n}=25)$ was normo-albuminuric $(\mathrm{ACR}<30 \mathrm{mg} / \mathrm{g})$ and Group II $(n=25)$ was albuminuric (ACR 30$300 \mathrm{mg} / \mathrm{g}$ ). Twenty five healthy age \& sex-matched children and adolescents acted as controls. Patients with cardiac, hepatic or renal disease other than DN were excluded from study.

All patients had a complete history taken with special emphasis on age of onset and duration of diabetes, insulin therapy and any history suggestive of renal complications, including albuminuria \& hypertension. A thorough physical examination was performed on all patients, laying stress on anthropometric measurements in terms of standing height, height standard deviation score (SDS), weight and weight SDS, body mass index (BMI), and BMI SDS for age and sex using software program Growth Vision 2.0 provided by Novo-Nordisk, Denmark. Further, blood pressure (BP) was measured and plotted on BP tables according to age and height percentile for boys and girls $^{7}$. Puberty was assessed using the Tanner staging $^{8}$.

Serum creatinine $(\mathrm{sCr})$ was determined and estimated glomerular filtration rate (eGFR) calculated by Schwartz formula: eGFR $=\mathrm{K} \times$ Height $(\mathrm{cm}) / \mathrm{sCr}$ $(\mathrm{mg} / \mathrm{dL})$. K was equal to 0.55 in 5-13 year old children and adolescent females, whilst it was 0.7 in adolescent males 9 . Lipid profile, including total cholesterol, serum high density lipoprotein-cholesterol (HDL-c), and triglyceride concentration, were determined enzymatically using commercially available kits on an auto-analyser (Olympus AU 480, USA). Low density lipoprotein-cholesterol (LDL-c) was estimated using Friedewald Formula ${ }^{10}$. The mean of glycosylated haemoglobin $(\mathrm{HbA} 1 \mathrm{c})$ values in the last year were recorded. Mean values for fasting and postprandial plasma glucose readings were calculated from the patients' notes in the previous month.

In addition, first-morning urine samples were collected. Complete urine analysis was performed and albuminuria was assessed in the absence of confounders namely urinary tract infections, exercise, and menstrual bleeding. ACR was determined by the immune-nephelometric method on Prospec Siemens, Siemens Healthcare Diagnostic Inc. Newark, DE 19714 U.S.A ${ }^{11}$. Albuminuria was confirmed by two ACR $>30 \mathrm{mg} / \mathrm{g}$ on 2 separate occasions. Urinary IL6 and TNF- $\alpha$ levels were assayed for patients and controls using a commercial enzyme-linked immunosorbent assay (ELISA) kits (Human IL-6 ELISA Kit. Catalog No: E0079h; Human TNF- $\alpha$
ELISA Kit. Catalog No: E0113h) in accord with the manufacturer's instructions. Urinary levels of cytokines were corrected by urinary creatinine $(\mathrm{Cr})$ concentration and expressed as urinary IL-6/Cr ratio and TNF- $\alpha / \mathrm{Cr}$ ratio.

Statistical analysis was done using the Statistical Package for the Social Sciences version 22. Data normally distributed were expressed as mean \pm SD and compared by ANOVA and Student $t$-test. Data not normally distributed were expressed as median and interquartile range (IQR). Shapiro-Wilk test was utilized to test if continuous variables were normally distributed. Comparison of the ratios between the studied groups was done using Kruskal Wallis test and Mann Whitney test as posthoc multiple 2-group comparisons after applying Bonferroni adjustment of multiple comparisons. Frequency differences were assessed using Chisquare test. Correlation between variables was performed utilising Spearman rank correlation equation. Multivariate linear regression analysis was utilised to test for the independent predictors of studied ratios in each of the diseased groups. Receiver operator characteristic (ROC) curves were constructed to assess reliability of urinary IL6/Cr ratio and $\mathrm{TNF}-\alpha / \mathrm{Cr}$ ratio in early detection of albuminuria. The area under the curve (AUC) was considered significant if $>0.6$ with a significant $p$ value. Two-sided $\mathrm{p}$-value $<0.05$ was considered statistically significant.

Ethical issues: Informed consent was obtained from parents of all patients before inclusion in the study. All the procedures followed were in accordance with the ethical standards of the responsible committee on human experimentation (the ethical committee of the Pediatric Department, Faculty of Medicine, Cairo University, and received as well, the approval of the Research Ethics Committee, Faculty of Medicine, Cairo University, date of approval: May 8, 2016, approval no. I-020315 and I-030315) and with the Helsinki Declaration of 2013.

\section{Results}

Of the 50 children and adolescents with T1DM, 26 were female and 24 were male. Group I had 10 girls and 15 boys with a mean age of $13.04 \pm 2.76$ years. Group II had 16 girls and 9 boys with a mean age of $13.64 \pm 3.28$ years. Among the 25 healthy, age and sex-matched controls, 13 were female and 12 were male. Their ages ranged from 8 to 18 years with a mean age of $13 \pm 2.75$ years. Apart from the significantly higher systolic and diastolic blood pressures in albuminuric patients, no significant differences were noted regarding clinical and demographic data between both patient groups. Regarding the laboratory findings, there was only a significantly higher mean fasting plasma glucose level in the albuminuric patients (Table 1). 
Table 1: Clinical, demographic and laboratory data of normo-albuminuric and albuminuric groups

\begin{tabular}{|c|c|c|c|}
\hline Parameters & $\begin{array}{l}\text { Normo-albuminuric } \\
\text { group }(n=25)\end{array}$ & $\begin{array}{l}\text { Albuminuric } \\
\text { group }(n=25)\end{array}$ & $p$ \\
\hline Diabetes duration (years) Mean \pm SD & $7.32 \pm 2.14$ & $7.88 \pm 2.99$ & 0.450 \\
\hline Age of onset (years) Median (IQR) & $6(3)$ & $5(3)$ & 0.761 \\
\hline Insulin dose (IU/kg/day) Mean \pm SD & $1.36 \pm 0.49$ & $1.28 \pm 0.46$ & 0.554 \\
\hline Height $(\mathrm{cm})$ Mean \pm SD & $143.02 \pm 12.18$ & $145.21 \pm 14.46$ & 0.565 \\
\hline Height standard deviation score Median (IQR) & $-1.5(-1.7)$ & $-1.13(-2.02)$ & 0.62 \\
\hline Weight $(\mathrm{kg})$ Mean \pm SD & $40.12 \pm 10.94$ & $43.7 \pm 13.12$ & 0.300 \\
\hline Weight standard deviation score Median (IQR) & $-0.5(-0.8)$ & $-0.2(-0.59)$ & 0.567 \\
\hline Body mass index $\left(\mathrm{kg} / \mathrm{m}^{2}\right)$ Mean \pm SD & $19.28 \pm 3.02$ & $20.26 \pm 2.99$ & 0.256 \\
\hline Body mass index standard deviation score Median (IQR) & $0.4(0.61)$ & $0.5(0.91)$ & 0.58 \\
\hline Systolic blood pressure $(\mathrm{mmHg})$ Mean \pm SD & $107.96 \pm 10.22$ & $116.2 \pm 15.56$ & $0.032 *$ \\
\hline Diastolic blood pressure $(\mathrm{mmHg})$ Mean $\pm \mathrm{SD}$ & $70.4 \pm 8.53$ & $74.52 \pm 18.38$ & $0.029 *$ \\
\hline Mean fasting plasma glucose $(\mathrm{mg} / \mathrm{dl})$ Mean $\pm \mathrm{SD}$ & $141.5(60.7)$ & $165.3(66.9)$ & $0.02 *$ \\
\hline Mean postprandial plasma glucose (mg/dl) Median (IQR) & $220(75)$ & $253.4(48.5)$ & 0.097 \\
\hline Glycosylated haemoglobin (\%) Mean \pm SD & $8.75 \pm 1.62$ & $9.38 \pm 2.26$ & 0.266 \\
\hline Serum creatinine $(\mathrm{mg} / \mathrm{dl})$ Mean $\pm \mathrm{SD}$ & $0.69 \pm 0.21$ & $0.62 \pm 0.13$ & 0.128 \\
\hline Glomerular filtration rate $\left(\mathrm{ml} / \mathrm{min} / 1.73 \mathrm{~m}^{2}\right)$ Mean $\pm \mathrm{SD}$ & $119.51(45.6)$ & $141.17(39.7)$ & 0.138 \\
\hline Cholesterol (mg/dl) Median (IQR) & $157(27)$ & $170(56)$ & 0.554 \\
\hline Triglycerides (mg/dl) Median (IQR) & $90(52)$ & $66(55)$ & 0.281 \\
\hline High density lipoprotein-cholesterol (mg/dl) Mean \pm SD & $46.35 \pm 10.14$ & $51.00 \pm 8.38$ & 0.083 \\
\hline Low density lipoprotein-cholesterol (mg/dl) Median (IQR) & $90(37.7)$ & $106(44)$ & 0.467 \\
\hline Albumin/creatinine ratio $(\mathrm{mg} / \mathrm{g})$ Median (IQR) & $10.4(7.8)$ & $57.4(49.5)$ & $<0.001^{*}$ \\
\hline
\end{tabular}

For Mean \pm SD 'Student t-test' was used as test of significance. For Median (IQR) 'Mann Whitney test' was used. ${ }^{*} p<0.05$ IQR - interquartile range; IU—international unit; SD—standard deviation

Table 2 shows a significant difference between urinary IL-6/Cr ratio among the studied groups. The albuminuric patients had significantly higher urinary IL-6/Cr ratio when compared to normoalbuminuric patients or controls. However, we did not observe varying $\mathrm{TNF}-\alpha / \mathrm{Cr}$ ratio in the studied groups, or between albuminuric and normo- albuminuric patients or controls. Similarly, there was no significant difference in urinary IL-6 and TNF- $\alpha$ levels between the studied groups. Nonetheless, there was a significant correlation between urinary IL- 6 and TNF- $\alpha$ among the studied patients $(p=0.018)$ and controls $(p=0.004)$.

Table 2: Urinary IL-6, TNF- $\alpha$ and their Cr ratio in the studied groups

\begin{tabular}{|c|c|c|c|c|}
\hline \multirow[t]{2}{*}{ Urinary cytokines } & $\begin{array}{l}\text { Normo-albuminuric group } \\
\qquad(\mathrm{n}=25)\end{array}$ & $\begin{array}{c}\text { Albuminuric group } \\
(n=25)\end{array}$ & $\begin{array}{c}\text { Controls } \\
\mathbf{n}=\mathbf{2 5} \\
\end{array}$ & p \\
\hline & Median (IQR) & Median (IQR) & Median (IQR) & \\
\hline IL-6 (pg/ml) & $25(5)$ & $25(10)$ & $20(20)$ & 0.22 \\
\hline IL-6/Cr ratio & $0.23(0.5)$ & $0.37(7.91)$ & $0.2(0.57)$ & $0.018^{*}$ \\
\hline \multirow[t]{3}{*}{$(\mathrm{pg} / \mathrm{mg})$} & & & & $0.23^{\mathrm{a}}$ \\
\hline & & & & $0.01 * \mathrm{~b}$ \\
\hline & & & & $0.04 * \mathrm{c}$ \\
\hline TNF- $\alpha(\mathrm{pg} / \mathrm{ml})$ & $20(10)$ & $15(10)$ & $20(15)$ & 0.15 \\
\hline TNF- $\alpha /$ Cr ratio & $0.75(0.4)$ & $0.8(0.5)$ & $0.83(0.55)$ & 0.7 \\
\hline \multirow[t]{3}{*}{$(\mathrm{pg} / \mathrm{mg})$} & & & & $0.56^{\mathrm{a}}$ \\
\hline & & & & $0.4^{\mathrm{b}}$ \\
\hline & & & & $0.89^{c}$ \\
\hline
\end{tabular}

Not normally distributed data were expressed as Median (IQR) and compared by the Kruskal-Wallis or MannWhitney U test. Cr-creatinine, IL-6-interleukin-6, IQR-interquartile range; TNF- $\alpha$-tumor necrosis factor alpha * Significant a. Normo-albuminuric group versus Control group b. Albuminuric group versus Control group c. Normo-albuminuric group versus Albuminuric group

Urinary IL-6/Cr ratio was negatively correlated with the duration of diabetes $(r=-0.43, p=0.029)$, and positively correlated with the urinary TNF- $\alpha$ level $(\mathrm{r}=0.54, \mathrm{p}=0.005)$ in albuminuric patients, and it also had a negative correlation with fasting plasma glucose $(\mathrm{r}=-0.62, \mathrm{p}=0.001)$ in normo- albuminuric patients (Table 3). A multiple regression analysis was performed between urinary IL-6/Cr ratio and diabetes duration as well as urinary TNF- $\alpha$ level, but no statistically significant association was found. 
Urinary $\mathrm{TNF}-\alpha / \mathrm{Cr}$ ratio had a positive correlation with duration of diabetes $(\mathrm{r}=0.48, \mathrm{p}=0.01)$ and systolic blood pressure $(\mathrm{r}=0.4, \mathrm{p}=0.04)$ in normoalbuminuric patients, and also with LDL-c $(\mathrm{r}=0.41$, $\mathrm{p}=0.03$ ) in albuminuric patients while it had a negative one with urinary IL-6 level in both groups $(\mathrm{r}=-0.49, \mathrm{p}=0.01)(\mathrm{r}=-0.68, \mathrm{p}=0.00)($ Table 4$) . \mathrm{A}$ multiple regression analysis was performed between urinary $\mathrm{TNF}-\alpha / \mathrm{Cr}$ ratio and diabetes duration, systolic blood pressure (SBP), LDL-c as well as urinary IL-6 level, but no statistically significant correlation was reported. Similarly, there was no significant correlation between either urinary IL-6 or TNF- $\alpha$ among studied patient groups as regards any of the clinical or laboratory data (Tables 3 and 4).

Table 3: Correlation between urinary IL-6 and IL-6/Cr ratio with the patients' clinical data and laboratory findings

\begin{tabular}{|c|c|c|c|c|c|c|c|c|}
\hline \multirow{3}{*}{ Parameters } & \multicolumn{4}{|c|}{ Urinary IL-6 (pg/ml) } & \multicolumn{4}{|c|}{ Urinary IL-6/Cr ratio (pg/mg) } \\
\hline & \multicolumn{2}{|c|}{$\begin{array}{c}\text { Normo- } \\
\text { albuminuric group } \\
\mathbf{n}=25\end{array}$} & \multicolumn{2}{|c|}{$\begin{array}{l}\text { Albuminuric } \\
\text { group } \\
\mathbf{n}=\mathbf{2 5}\end{array}$} & \multicolumn{2}{|c|}{$\begin{array}{c}\text { Normo-albuminuric } \\
\begin{array}{c}\text { group } \\
\mathbf{n}=\mathbf{2 5}\end{array}\end{array}$} & \multicolumn{2}{|c|}{$\begin{array}{l}\text { Albuminuric group } \\
\mathbf{n}=\mathbf{2 5}\end{array}$} \\
\hline & $\mathbf{r}$ & $p$ & $\mathbf{r}$ & $p$ & $\mathbf{r}$ & $p$ & $\mathbf{r}$ & $p$ \\
\hline Diabetes duration (years) & -0.395 & 0.051 & -0.269 & 0.193 & -0.12 & 0.55 & -0.43 & $0.02 *$ \\
\hline Age of onset (years) & -0.072 & 0.732 & 0.044 & 0.836 & -0.09 & 0.64 & 0.21 & 0.3 \\
\hline Insulin dose (IU/kg/day) & -0.080 & 0.704 & 0.070 & 0.740 & -0.2 & 0.33 & 0.1 & 0.6 \\
\hline Height standard deviation score & 0.354 & 0.053 & 0.056 & 0.789 & 0.15 & 0.45 & -0.08 & 0.67 \\
\hline Weight standard deviation score & 0.215 & 0.302 & 0.121 & 0.565 & 0.28 & 0.17 & -0.07 & 0.72 \\
\hline BMI standard deviation score & 0.136 & 0.517 & 0.162 & 0.439 & 0.25 & 0.22 & 0.04 & 0.83 \\
\hline Systolic blood pressure (mmHg) & -0.332 & 0.105 & -0.078 & 0.711 & 0.007 & 0.97 & -0.12 & 0.56 \\
\hline Diastolic blood pressure $(\mathrm{mmHg})$ & -0.187 & 0.370 & 0.165 & 0.430 & 0.13 & 0.51 & 0.02 & 0.9 \\
\hline Fasting plasma glucose $(\mathrm{mg} / \mathrm{dl})$ & -0.228 & 0.274 & 0.019 & 0.927 & -0.62 & $0.001 *$ & 0.09 & 0.65 \\
\hline Glycosylated haemoglobin (\%) & -0.240 & 0.249 & -0.309 & 0.133 & 0.19 & 0.34 & -0.26 & 0.2 \\
\hline Serum Creatinine $(\mathrm{mg} / \mathrm{dl})$ & -0.275 & 0.184 & -0.043 & 0.840 & 0.001 & 0.99 & -0.004 & 0.98 \\
\hline GFR $\left(\mathrm{ml} / \mathrm{min} / 1.73 \mathrm{~m}^{2}\right)$ & 0.041 & 0.846 & 0.070 & 0.741 & -0.1 & 0.62 & -0.06 & 0.76 \\
\hline Cholesterol (mg/dl) & -0.192 & 0.357 & -0.199 & 0.341 & -0.2 & 0.31 & 0.02 & 0.89 \\
\hline Triglycerides (mg/dl) & -0.082 & 0.696 & 0.007 & 0.974 & -0.06 & 0.76 & 0.22 & 0.28 \\
\hline HDL-c (mg/dl) & 0.262 & 0.206 & -0.193 & 0.356 & 0.15 & 0.44 & -0.21 & 0.31 \\
\hline LDL-c (mg/dl) & -0.135 & 0.520 & -0.096 & 0.649 & -0.11 & 0.59 & 0.18 & 0.37 \\
\hline ACR (mg/gm) & -0.162 & 0.439 & 0.216 & 0.299 & 0.32 & 0.11 & 0.16 & 0.43 \\
\hline TNF- $\alpha(\mathrm{pg} / \mathrm{ml})$ & - & - & - & - & 0.25 & 0.22 & 0.54 & $0.005^{*}$ \\
\hline
\end{tabular}

$r-$ Spearman coefficient, $p$ value was significant at $p<0.05 . *$ Significant

ACR - albumin/creatinine ratio; BMI - body mass index; GFR-glomerular filtration rate; High density lipoprotein-cholesterol; IU international unit; LDL-c_Low density lipoprotein-cholesterol; SDS-standard deviation score; TNF- $\alpha$-tumor necrosis factor alpha

Table 4: Correlation between urinary $T N F-\alpha$ and $T N F-\alpha / C r$ ratio with the patients' clinical data and laboratory findings

\begin{tabular}{|c|c|c|c|c|c|c|c|c|}
\hline \multirow{3}{*}{ Parameters } & \multicolumn{4}{|c|}{ Urinary TNF- $\alpha(\mathrm{pg} / \mathrm{ml})$} & \multicolumn{4}{|c|}{ Urinary TNF- $\alpha / \mathrm{Cr}$ ratio $(\mathrm{pg} / \mathrm{mg})$} \\
\hline & \multicolumn{2}{|c|}{$\begin{array}{c}\text { Normo- } \\
\text { albuminuric group } \\
(\mathrm{n}=\mathbf{2 5})\end{array}$} & \multicolumn{2}{|c|}{$\begin{array}{l}\text { Albuminuric group } \\
\qquad(\mathrm{n}=\mathbf{2 5})\end{array}$} & \multicolumn{2}{|c|}{$\begin{array}{c}\text { Normo- } \\
\text { albuminuric group } \\
(\mathrm{n}=25)\end{array}$} & \multicolumn{2}{|c|}{$\begin{array}{l}\text { Albuminuric } \\
\text { group }(n=25)\end{array}$} \\
\hline & $\mathbf{r}$ & $p$ & $\mathbf{r}$ & $p$ & $\mathbf{r}$ & $p$ & $\mathbf{r}$ & $p$ \\
\hline Diabetes duration (years) & 0.258 & 0.213 & -0.207 & 0.321 & 0.48 & $0.01 *$ & 0.05 & 0.8 \\
\hline Age of onset (years) & -0.034 & 0.870 & 0.277 & 0.180 & -0.09 & 0.66 & 0.29 & 0.14 \\
\hline Insulin dose (IU/kg/day) & -0.273 & 0.187 & 0.155 & 0.458 & 0.01 & 0.95 & 0.003 & 0.99 \\
\hline Height standard deviation score & -0.393 & 0.052 & -0.125 & 0.55 & -0.56 & $0.003 *$ & -0.004 & 0.98 \\
\hline Weight standard deviation score & -0.321 & 0.118 & 0.024 & 0.909 & -0.46 & $0.01 *$ & -0.06 & 0.74 \\
\hline Body mass index SDS & -0.122 & 0.563 & -0.006 & 0.979 & -0.23 & 0.26 & -0.26 & 0.2 \\
\hline Systolic blood pressure (mmHg) & 0.287 & 0.164 & 0.307 & 0.136 & 0.4 & 0.04 & 0.29 & 0.15 \\
\hline Diastolic blood pressure $(\mathrm{mmHg})$ & 0.025 & 0.906 & 0.352 & 0.085 & 0.09 & 0.66 & 0.05 & 0.8 \\
\hline Fasting plasma glucose $(\mathrm{mg} / \mathrm{dl})$ & -0.262 & 0.206 & 0.212 & 0.310 & -0.23 & 0.26 & 0.11 & 0.57 \\
\hline Glycosylated hemoglobin (\%) & 0.064 & 0.762 & -0.297 & 0.149 & 0.07 & 0.71 & 0.15 & 0.47 \\
\hline Serum creatinine $(\mathrm{mg} / \mathrm{dl})$ & 0.236 & 0.256 & 0.078 & 0.710 & 0.36 & 0.07 & 0.12 & 0.56 \\
\hline GFR $\left(\mathrm{ml} / \mathrm{min} / 1.73 \mathrm{~m}^{2}\right)$ & -0.275 & 0.183 & 0.042 & 0.841 & -0.23 & 0.25 & -0.02 & 0.9 \\
\hline Cholesterol (mg/dl) & -0.237 & 0.254 & 0.236 & 0.255 & -0.16 & 0.44 & 0.37 & 0.06 \\
\hline Triglycerides (mg/dl) & 0.285 & 0.168 & 0.022 & 0.918 & 0.18 & 0.38 & -0.04 & 0.84 \\
\hline HDL-c (mg/dl) & -0.268 & 0.195 & -0.074 & 0.727 & -0.36 & 0.07 & 0.21 & 0.29 \\
\hline LDL-c (mg/dl) & -0.195 & 0.349 & 0.387 & 0.056 & -0.13 & 0.5 & 0.41 & $0.03^{*}$ \\
\hline Albumin/creatinine ratio $(\mathrm{mg} / \mathrm{g})$ & 0.251 & 0.226 & -0.001 & 0.997 & 0.33 & 0.1 & -0.31 & 0.12 \\
\hline Interleukin-6 (pg/ml) & - & - & - & - & -0.49 & $0.01^{*}$ & -0.68 & $0.00^{*}$ \\
\hline
\end{tabular}

$r-$ Spearman coefficient, $p$ value was significant at $p<0.05 . *$ Significant

GFR - glomerular filtration rate; HDL-c_-High density lipoprotein-cholesterol; IU-international unit; LDL-c-Low density lipoproteincholesterol; SDS - standard deviation score; TNF- $\alpha$-tumor necrosis factor alpha;

Urinary IL-6/Cr ratio $\geq 0.24 \mathrm{pg} / \mathrm{mg}$ was a significant cutoff value to detect albuminuria with $72 \%$ sensitivity and $52 \%$ specificity $(p=0.04)$ which was documented by ROC curve $(\mathrm{AUC}=0.666)$ indicating that, urinary IL-6/Cr ratio could be a potential marker for early diagnosis of DN (Figure $1)$. 


\section{ROC Curve}

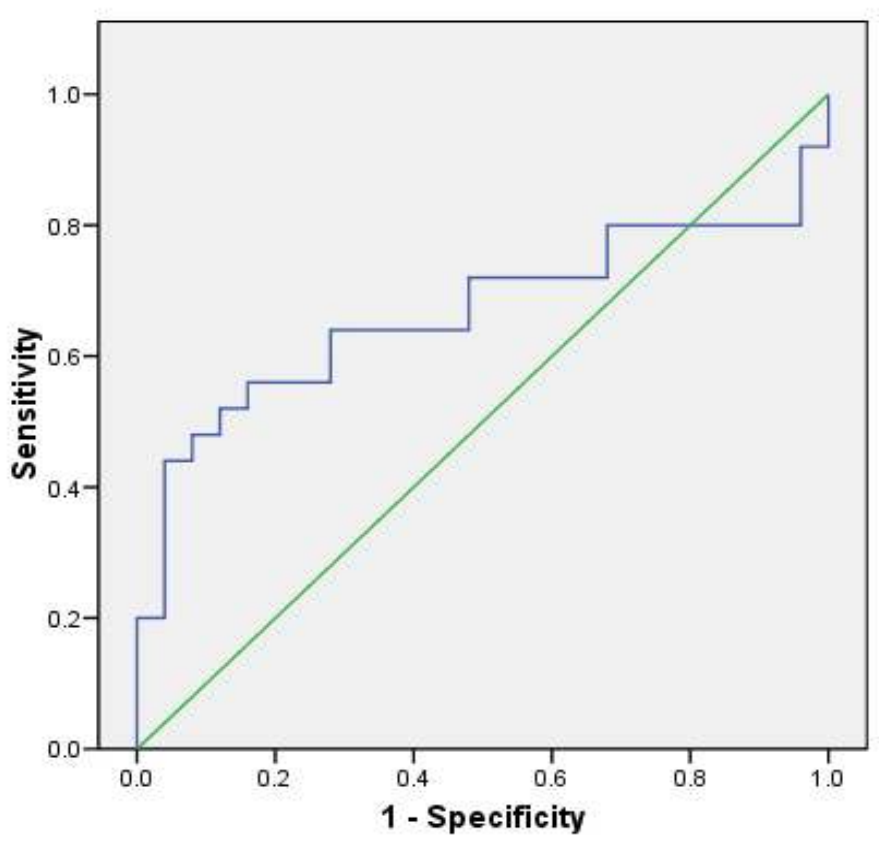

Figure 1 ROC curve of urinary $I L-6 / C r$ ratio cutoff value to detect albuminuria

IL-6/ Cr ratio $\geq 0.24 \mathrm{pg} / \mathrm{mg}$ showed a significant cutoff value to detect albuminuria with $72 \%$ sensitivity and $52 \%$ specificity $(p=0.04 *)$.

$I L-6 / C r$ ratio- interleukin-6/creatinine ratio; Area under the curve $(A U C)=0.666$.

$* p$ value was significant $(p<0.05)$

\section{Discussion}

As the mechanisms responsible for development of renal injury are still unclear, inflammation had a critical role in the development of early injury in preclinical $\mathrm{DN}^{12}$. Therefore, we were encouraged to assess urinary markers of inflammation which could predict early DN in children and adolescents with T1DM. In our study, elevated urinary IL-6/Cr ratio was reported with the worsening of albuminuria, since higher values were noted in the albuminuric in comparison with normoalbuminuric patients or controls. In addition, urinary IL-6/Cr ratio $\geq 0.24 \mathrm{pg} / \mathrm{mg}$ was a significant cutoff value to detect albuminuria with $72 \%$ sensitivity and $52 \%$ specificity $(p=0.04)$. We did not note significant differences in $\mathrm{TNF}-\alpha / \mathrm{Cr}$ ratio between the studied groups, or between albuminuric and normo-albuminuric patients or controls. These findings support the inflammatory role of urinary IL-6 and its subsequent increase in DN indicating that urinary IL-6/Cr ratio could be a potential marker of early DN. This is in accordance with Pestana et $a l^{12}$ who reported elevated urinary IL$6 / \mathrm{Cr}$ ratio in patients with micro- and macroalbuminuria in comparison with normoalbuminuric patients and controls. Further, Vaidya et $a l^{13}$ noted that micro-albuminuric patients had significantly higher urinary IL-6 than normoalbuminuric patients. Furthermore, Wolkow et $a l^{14}$ reported that urinary IL-6 concentrations were comparable in the patients with normal renal functions either normo-albuminuric or microalbuminuric, whereas they were significantly higher in the micro-albuminuric group with a progressive decline of renal functions. Nevertheless, urinary TNF- $\alpha$ was not detectable in most patients, and they concluded that urinary IL-6 was associated with declining renal function, but not linked to microalbuminuria. This was contrary to Klimontov et $a l^{15}$ and Pestana et $a l^{12}$ who found that urinary TNF- $\alpha$ level in patients with micro- and macro-albuminuria were significantly increased compared to controls.

On univariate analysis, there was a significant association between urinary $\mathrm{IL}-6 / \mathrm{Cr}$ ratio with diabetes duration, fasting plasma glucose (FPG) and urinary TNF- $\alpha$ level. Further, we observed a significant correlation between the urinary TNF$\alpha / \mathrm{Cr}$ ratio with duration of diabetes, SBP, low density lipoprotein-cholesterol, and urinary IL-6 level. However, no significant association was documented when the markers were entered into the multiple regression model. This lack of significant correlation in our study between urinary cytokines and all the studied clinical and laboratory data among the patient groups might demonstrate the complex nature of the disease and reflect the persistent inflammatory milieu in T1DM whether of long or short duration. This is consistent with 
Pestana et $a l^{12}$ who studied urinary IL-6/Cr ratio and TNF- $\alpha / \mathrm{Cr}$ ratio in T1DM patients and found that urinary IL-6/Cr ratio was not correlated with sCr, albuminuria, eGFR, FPG, and HbAlc. However, urinary $\mathrm{TNF}-\alpha / \mathrm{Cr}$ ratio was reported to have been positively correlated with $\mathrm{sCr}$ and albuminuria, albeit negatively correlated with eGFR. Vaidya et $a l^{13}$ reported that microalbuminuria progression and regression were unrelated to the urinary IL-6 level.

We recorded significantly higher SBP and DBP measurements in patients with albuminuria compared to normo-albuminuric patients. This was in concordance with Amritanshu et $a l^{16}$ and Ahmed $^{17}$ who reported that in patients with microalbuminuria, both SBP and DBP values were significantly higher in comparison with those having normo-albuminuria. On the other hand, Suh et $a l^{18}$ observed that SBP and DBP did not differ between the normo-albuminuric and microalbuminuric groups. We also found albuminuric patients had significantly higher FPG levels in comparison to normo-albuminuric patients. This was endorsed by Shelbaya et $a l^{19}$ and Pestana et $a l^{12}$ while we did not report any statistically significant difference as regards $\mathrm{HbA} 1 \mathrm{c}$. This was similar to Shelbaya et $a l^{19}$ and Suh et $a l^{18}$. Nevertheless, this was in contrast to the findings of Ahmed $^{17}$ and Pestana et $a l^{12}$ whose studies revealed statistically higher HbA1c levels among the microalbuminuric group. These attractive findings support that $\mathrm{HbAlc}$ values do not exactly consider the factual state of glycaemic control in some circumstances with rapid alterations in glycaemic control and anaemia and patients with variant haemoglobin ${ }^{20}$.

In addition, no statistically significant difference was observed between our patient groups as regards $\mathrm{sCr}$ and eGFR, which was in agreement with $\mathrm{Ahmed}^{17}$ and Suh et $a l^{18}$. These findings support that $\mathrm{sCr}$ in diabetic patients does not indicate the early signs of diminished renal functions ${ }^{21}$. However, Pestana et $a l^{12}$ revealed that the albuminuric patients had significantly higher $\mathrm{sCr}$ and lower eGFR than the normo-albuminuric patients. The fact that this was a case-control study with relatively few subjects is a limitation. More extensive studies of a longitudinal nature are required to confirm the association between urinary cytokines such as IL- 6 and TNF- $\alpha$ with the renal pathophysiology in children with T1DM.

\section{Conclusions}

Urinary IL-6/Cr ratio was elevated with worsening of the nephropathy since higher values were observed in the albuminuric patients when compared to normo-albuminuric patients and controls. Urinary $\mathrm{IL}-6 / \mathrm{Cr}$ ratio $\geq 0.24 \mathrm{pg} / \mathrm{mg}$ was a significant cutoff value to detect albuminuria with $72 \%$ sensitivity and $52 \%$ specificity $(\mathrm{p}=0.04)$. Urinary IL-6/Cr ratio seems to be a promising new marker for early detection of $\mathrm{DN}$ in patients with T1DM, while urinary TNF- $\alpha / \mathrm{Cr}$ ratio showed no significant difference between diabetic patients and controls.

\section{Acknowledgments}

We would like to express our sincere thanks to all children and their parents who participated in this work. We would like to express our appreciation to our colleagues and nurses at Diabetes Endocrine and Metabolism Pediatric Unit (DEMPU) who facilitated this work.

\section{References}

1. Zhang J, Liu J, Qin X. Advances in early biomarkers of diabetic nephropathy. Rev Assoc Med Bras. 2018; 64 (1): 85-92.

https://doi.org/10.1590/1806-9282.64.01.85 PMid: 29561946

2. Liu LH, Sun G. Novel biomarkers for early diagnosis and progression of diabetic nephropathy. ARC Journal of Diabetes and Endocrinology 2015; 1:14-30. https://doi.org/10.20431/2455-5983.0101003

3. Campion CG, Sanchez-Ferras O, Batchu SN. Potential role of serum and urinary biomarkers in diagnosis and prognosis of diabetic nephropathy. Canadian Journal of Kidney Health and Disease 2017; 4: 2054358117705371. https://doi.org/10.1177/2054358117705371 PMid: 28616250 PMCid: PMC5461910

4. Papadopoulou-Marketou N, Kanaka-Gantenbein C, Marketos N, Chrousos GP, Papassotiriou I. Biomarkers of diabetic nephropathy: A 2017 update. Critical Reviews in Clinical Laboratory Sciences 2017; 54(5):326-42. https://doi.org/10.1080/10408363.2017.137768 2 PMid: 28956668

5. Domingueti CP, Fóscolo RB, Reis JS, Campos FM, Dusse LM, Carvalho MD, et al. Association of haemostatic and inflammatory biomarkers with nephropathy in type 1 diabetes mellitus. Journal of Diabetes Research 2016; 2016: 2315260.

https://doi.org/10.1155/2016/2315260

PMid: 26770985 PMCid: PMC4684869

6. Aghadavod E, Khodadadi S, Baradaran A, Nasri P, Bahmani M, Rafieian-Kopaei M. Role of oxidative stress and inflammatory factors in diabetic kidney disease. Iranian Journal of Kidney Diseases 2016; 10(6):337-43. 
7. Falkner B, Daniels SR, Flynn JT, Gidding S, Green LA, Ingelfinger JR, et al. The fourth report on the diagnosis, evaluation, and treatment of high blood pressure in children and adolescents. Pediatrics 2004; 114(2 III):555-76. https://doi.org/10.1542/peds.114.2.S2.555

8. Tanner JM, Whitehouse RH. Longitudinal standards for height, weight, height velocity, weight velocity, and stages of puberty. Archives of Disease in Childhood 1976; 51(3):170-9. https://doi.org/10.1136/adc.51.3.170 PMid: 952550 PMCid: PMC1545912

9. Vogt BA, Avner ED. Renal failure. In: Kliegman RM, editors. Nelson Textbook of Paediatrics, 18th ed. 2008. Chapter 535; p. 2206-14.

10. Friedewald WT, Levy RI, Fredrickson DS. Estimation of the concentration of low-density lipoprotein cholesterol in plasma, without use of the preparative ultracentrifuge. Clinical Chemistry 1972; 18(6): 499-502.

11. Rowe DJ, Dawnay A, Watts GF. Microalbuminuria in diabetes mellitus: review and recommendations for the measurement of albumin in urine. Annals of Clinical Biochemistry 1990; 27(4):297-312. https://doi.org/10.1177/000456329002700404 PMid: 2206092

12. Pestana RM, Domingueti CP, Duarte RC, Fóscolo RB, Reis JS, Rodrigues AM, et al. Cytokines profile and its correlation with endothelial damage and oxidative stress in patients with type 1 diabetes mellitus and nephropathy. Immunologic Research 2016; 64(4):951-60.

https://doi.org/10.1007/s12026-016-8806-X PMid: 27307060

13. Vaidya VS, Niewczas MA, Ficociello LH, Johnson AC, Collings FB, Warram $\mathrm{JH}$, et al. Regression of microalbuminuria in type 1 diabetes is associated with lower levels of urinary tubular injury biomarkers, kidney injury molecule-1, and N-acetyl- $\beta$-D-glucosaminidase. Kidney International 2011; 79(4):464-70. https://doi.org/10.1038/ki.2010.404 PMid: 20980978 PMCid: PMC3033751

14. Wolkow PP, Niewczas MA, Perkins B, Ficociello LH, Lipinski B, Warram $\mathrm{JH}$, et al. Association of urinary inflammatory markers and renal decline in microalbuminuric type 1 diabetics. Journal of the American Society of Nephrology 2008; 19(4):789-97.

https://doi.org/10.1681/ASN.2007050556

PMid: 18256362 PMCid: PMC2390964
15. Klimontov VV, Parfent'eva EM, Romanov VV, Nadeev AP. Urinary excretion of fibrogenic and antifibrotic growth factors in type 1 diabetic patients: the interrelationship with diabetic nephropathy. Ter Arkh. 2012; 84(6):36-40.

16. Amritanshu K, Kumar A, Anand K, Garg N, Banerjee DP. Clinical profile and factors associated with microalbuminuria in type 1 diabetes mellitus in children and adolescents. International Journal of Research in Medical Sciences 2015; 3(5): 1247-51. https://doi.org/10.5455/23206012.ijrms201505 38

17. Ahmed AE. Evaluation of serum cystatin $\mathrm{c}$ in type 1 diabetic children and adolescents as an early indicator of diabetic nephropathy. Journal of American Science 2015; 11(5): 129-36.

18. Suh JS, Kim SH, Cho KS, Jung IA, Cho WK, Jeon YJ, et al. Urinary markers in the early stage of nephropathy in patients with childhood-onset type 1 diabetes. Pediatric Nephrology 2016; 31 (4):623-31. https://doi.org/10.1007/s00467-015-3253-9 PMid: 26525196

19. Shelbaya S, Amer H, Seddik S, Allah AA, Sabry IM, Mohamed T, et al. Study of the role of interleukin-6 and highly sensitive C-reactive protein in diabetic nephropathy in type 1 diabetic patients. European Review for Medical and Pharmacological Sciences 2012; 16(2):176-82.

20. Koga M. Glycated albumin; clinical usefulness. Clin Chim Acta. 2014; 433: 96-104. https://doi.org/10.1016/j.cca.2014.03.001 PMid: 24631132

21. Chae HW, Shin JI, Kwon AR, Kim HS, Kim DH. Spot urine albumin to creatinine ratio and serum cystatin $\mathrm{C}$ are effective for detection of diabetic nephropathy in childhood diabetic patients. Journal of Korean Medical Science 2012; 27(7): 784-7. https://doi.org/10.3346/jkms.2012.27.7.784 PMid: 22787375 PMCid: PMC3390728 